\title{
Infancia y televisión: el papel de los reguladores independientes
}

\section{Childhood and Television: The Role of Independent Regulators}

Carmen Fuente Cobo, profesora de Ética y Deontología de la Información. Centro Universitario Villanueva (UCM)

Recibido: 17-X-2008 - Aceptado: 10-XII-2008

Resumen:

La protección de los menores constituye uno de los límites a las libertades de expresión y de información presentes en nuestro ordenamiento jurídico. Dicha protección se concreta en forma de normas relativas a la emisión de determinados tipos de contenidos audiovisuales que puedan afectar de manera negativa a los menores. En la mayor parte de los países de nuestro entorno, el control del cumplimiento de estas normas ha sido encomendado a entidades reguladoras independientes. El artículo describe y analiza el ejercicio de esta función de control por parte de Ofcom, Conseil Supérieur de l'Audiovisuel y Consell de l'Audiovisual de Catalunya.

Palabras clave:

Consejos Audiovisuales, protección de la infancia y la juventud, libertad de expresión y de información, autorregulación, co-regulación

Abstract:

One of the limits commonly accepted on freedom of expression and information is the protection due to the children and the youth. This protection usually takes the form of rules concerning the diffusion of audiovisual content which might affect negatively the intellectual, mental or moral development of minors. In most European countries the control and enforcement of these rules is in the hands of independent regulatory entities. This article describes and analyses how this function of control is exercised by three of the most relevant independent audiovisual authorities in Europe: Ofcom, Conseil Supérieur de l'Audiovisuel and Consell de l'Audiovisual de Catalunya.

Key words:

Protection of the children and the youth, independent audiovisual regulatory bodies, freedom of expression and information, self-regulation, co-regulation 


\section{Introducción}

La necesidad de establecer mecanismos de protección de los menores frente al posible impacto negativo de contenidos difundidos a través de los medios de comunicación audiovisuales es, quizás, el tema que mejor escenifica la tensión que se produce cuando a la obligación primaria de garantizar la libertad de expresión y de información, sustantiva y sostenedora de las demás libertades ${ }^{1}$, se añade la simultánea de asegurar la protección de otros bienes. Esta posibilidad de introducir límites a la libertad de expresión e información viene reconocida en nuestro ordenamiento constitucional, está amparada por el Tribunal Constitucional y es una constante en la doctrina de éste sobre protección de la infancia y la juventud (Linde y Vidal, 2007: 519).

En este sentido, la protección de la libertad en un entorno en el que es necesario a la vez proteger a los menores del impacto de contenidos no adecuados para ellos, exige plantearse cuáles son las garantías exigibles a lo largo de todo el proceso de concreción de las normas, evaluación del cumplimiento de las mismas e imposición de sanciones a los medios, de manera que dicho proceso cuente con el máximo de barreras de contención del elemento de discrecionalidad inevitable en relación con los contenidos y para el tipo de obligaciones a que nos referimos. Exige, además, asegurar en la medida de lo posible que el riesgo que se corre para la libertad esté justificado por el daño efectivamente causado o por la apreciación razonable y razonada de un riesgo de daño para los sujetos que se trata de proteger. La nueva Directiva 2007/65, que modifica la Directiva 89/552 de Televisión sin Fronteras² ${ }^{2}$ advierte de estos riesgos de manera muy clara señalando que "la disponibilidad de contenidos nocivos en los servicios de comunicación audiovisual sigue siendo motivo de preocupación para el legislador, el sector de medios y los padres. Habrá también nuevos desafíos, especialmente en relación con las nuevas plataformas y productos. En consecuencia, es necesario introducir normas que protejan el desarrollo físico, mental y moral del menor, así como la dignidad humana, en todos los servicios de comunicación audiovisual, incluida la comunicación comercial audiovisual”. E inmediatamente después, añade: "Se deben equilibrar cuidadosamente las medidas para proteger

\footnotetext{
1 Sin una comunicación pública libre, señala el Tribunal Constitucional, "quedarían vaciados del contenido real otros derechos que la Constitución consagra, reducidas a formas hueras las instituciones representativas y absolutamente falseado el principio de legitimidad democrática que enuncia el art.1.2 de la Constitución, y que es la base de toda nuestra ordenación jurídico-política” (TC 6/1981, de 16 de marzo)

2 Directiva 89/552/CEE del Consejo sobre la coordinación de determinadas disposiciones legales, reglamentarias y administrativas de los Estados miembros relativas al ejercicio de actividades de radiodifusión televisiva, modificada por la Directiva 97/36/CE del Parlamento Europeo y del Consejo de 30 de junio de 1997 y por la Directiva 2007/65/CE del Consejo, de 19 de diciembre (esta última, conocida y citada como Directiva sobre Servicios Audiovisuales),

3 Considerando 44
}

$74 \mid n^{\circ} 8$ | doxa.comunicación 
a los menores y la dignidad humana con el derecho fundamental a la libertad de expresión consagrado en la carta de los Derechos Fundamentales de la Unión Europea (...)”4.

Los comentarios que siguen a continuación tienen como objetivo identificar algunos de los temas centrales en lo que cabe fijarse a la hora de considerar tanto los riesgos para la libertad, como la eficacia protectora de la infancia de los mecanismos y medidas de control adoptados en determinados contextos regulatorios.

\section{Las entidades independientes de regulación del audiovisual}

La regulación del contenido de los medios audiovisuales en relación con los objetivos de protección de la infancia y la juventud está sujeta en Europa a unos principios comunes, establecidos principalmente a través de una norma central, la Directiva de Televisión sin Fronteras, junto a la que actúan otros documentos de referencia entre los que cabe citar, fundamentalmente, la Recomendación 98/560/CE del Consejo, de 24 de septiembre, relativa al desarrollo de la competitividad de la industria europea de servicios audiovisuales y de información mediante la promoción de marcos nacionales destinados a lograr un nivel de protección comparable y efectivo de los menores y de la dignidad humana.

Tras las modificaciones introducidas recientemente, las obligaciones contenidas en la Directiva de Televisión sin Fronteras que se refieren expresamente a la protección de los menores han quedado separadas de las relativas a la protección de la dignidad humana. En particular, la prohibición absoluta de contenidos que inciten al odio por motivos de raza, sexo, religión o nacionalidad, se ha llevado a un nuevo artículo para asegurar que dicha prohibición se extiende a todos los servicios de comunicación audiovisual, lo cual no sucede con las normas relativas a contenidos que puedan perjudicar a los menores, permitidos en determinadas condiciones de acceso restringido en función de horarios de emisión o mediante procedimientos técnicos de control de acceso.

De esta manera, las obligaciones específicas relativas a la protección de los menores contenidas en el artículo 22 permanecen inalteradas y son, en síntesis, las siguientes:

1. Prohibición de emitir "ningún programa que pueda perjudicar seriamente el desarrollo físico, mental o moral de los menores y, en particular, programas que incluyan escenas de pornografía o violencia gratuita”.

4 Considerando 45 
2. Prohibición de emitir "otros programas que puedan perjudicar el desarrollo físico, mental o moral de los menores” salvo en horarios restringidos o utilizando medidas técnicas que aseguren que los menores no ven o escuchan dichos programas.

3. Obligación de acompañar la emisión de estos programas, cuando se realice en abierto, de señales o advertencias acústicas y/o visuales.

4. En la transposición de las normas comunitarias a los diversos ordenamientos nacionales no siempre se ha seguido estrictamente el contenido de las mismas. Por ejemplo, en la norma española se elimina, dentro de los contenidos cuya emisión queda prohibida con carácter absoluto, la referencia explícita a los programas que incluyan escenas de pornografía o violencia gratuita (art.17,1) , que podrán emitirse pero sujetos a determinadas restricciones, siguiendo el ejemplo francés, que también elimina dicha prohibición total ${ }^{6}$, al igual que sucede en el caso de la regulación vigente en el Reino Unido ${ }^{7}$. Por el contrario, la Ley de la Comunicación de Cataluña de 2005 sigue de manera textual la norma comunitaria ${ }^{8}$.

En todos los países de la Unión Europea ${ }^{9}$, con la excepción de España, el control del cumplimiento de estas obligaciones ha sido depositado en manos de autoridades o entidades de regulación independientes, a partir de la premisa de que no sólo es poco conveniente dejar al Gobierno el control de un sector en el que éste es parte interesada, como titular y gestor de medios de titularidad pública, sino que además debe evitarse el riesgo de una intervención política sobre los contenidos por parte de los poderes públicos. Son éstas las razones que explican, en el panorama del derecho comparado, la necesidad de crear entidades independientes (Tornos, 2007: 157-186), aunque también se aducen razones de eficacia y eficiencia -la justicia es lenta y costosa- para justificar la puesta en marcha de este tipo de organismos, con carácter casi inevitable,

5 Ley 25/1994, de 12 de julio, por la que se incorpora al ordenamiento jurídico español la Directiva 89/552/CE, sobre la coordinación de disposiciones legales, reglamentarias y administrativas de los estados miembros, relativas al ejercicio de actividades de radiodifusión televisiva. Modificada por la Ley 22/1999, de 7 de junio, por la que se incorpora la Directiva 97/36 CE de 30 de junio.

6 Loi no 86-1067 du 30 septembre 1986 relative à la liberté de communication, art. 15 (modifié par la loi no 2000-719 du 1er août 2000 et par la loi no 2004-669 du 9 juillet 2004)

7 Actualizada en el código publicado por OFCOM que entró en vigor el 25 de julio de 2005 y que unifica las normas existentes hasta la fecha. La norma equivalente a la original de la Directiva comunitaria establece que "El material que pueda perjudicar seriamente el desarrollo físico, mental o moral de las personas menores de 18 años no debe ser emitido” (The Ofcom Broadcasting Code, Section 1, 1.1)

8 Art.81,3. "Los prestadores de servicios de radio o televisión no pueden ofrecer ningún contenido que pueda perjudicar seriamente el desarrollo físico, mental o moral de los menores. De una manera particular, se prohíbe la difusión, por parte de dichos prestadores, de contenidos pornográficos o de violencia gratuita".

9 La relación completa de países y sus respectivos organismos regulatorios puede consultarse en la web de la Plataforma Europea de Autoridades Reguladoras, www.epra.org 
frente al modelo tradicional de reparto de funciones entre el poder legislativo, que establece límites, y el poder judicial, que administra castigos (Betancor, 2007: 31-82).

Las entidades de este tipo más relevantes tienen atribuidas no sólo potestades de control y sanción, sino también de regulación, no tanto porque dicten normas o leyes, como sucede en el caso de la FCC americana, sino porque las interpretan y se encargan de aplicarlas (Arnanz, G.Castillejo y Fernández, 2004: 32 y ss.). Esta interpretación es, por otra parte, inevitable cuando se trata de asegurar el cumplimiento de las normas sobre contenidos audiovisuales, algunas de las cuales exigen una interpretación caso por caso, como veremos (Betancor, 2007: 61) $)^{10}$.

Desde las instituciones comunitarias se viene insistiendo desde hace años en la necesidad de establecer en todos los países autoridades reguladoras independientes, dotadas de capacidad y poderes suficientes para desarrollar su misión y con independencia asegurada a través de requerimientos exigentes en cuanto a su composición, organización y estatuto ${ }^{11}$. Cabe recordar, a este respecto, la comparecencia del comisario Marcelino Oreja ante la subcomisión del Congreso de los Diputados de RTVE el 11 de diciembre de 1998, durante la cual explicó que "la mejor forma de desempeñar estas funciones [de regulación] es a través de la creación de un organismo independiente de regulación del sector audiovisual, tanto público como privado, dotado de independencia, autonomía y medios que le permitan desarrollar estas funciones" (García Castillejo, 2003: 12).

La situación de España en el conjunto de países de la Unión Europea puede calificarse, sin duda, de anomalía no sólo porque constituye uno de los escasos ejemplos de regulación demandada por todas las partes, sin excepciones significativas ${ }^{12}$, sino porque - en la autorizada opinión de Joan Botella, catedrático de Ciencia Política de la Universidad Autónoma de Barcelona y presidente de la Plataforma Europea de Autoridades Reguladoras entre 2006 y 2007-, "lo que no tiene equivalente en las democracias avanzadas actuales es el

${ }^{10}$ No es posible, señala el autor, la administrativización del control de los contenidos en el sentido de un control mecánico, de simple comprobación de ciertas reglas y de aplicación de sanciones consiguientes porque este proceso de comprobación, cuando se trata del cumplimiento de los límites constitucionales a las libertades del artículo 20 de la Constitución Española, lleva aparejada una doble actividad adicional de fijación del alcance de los límites y de ponderación de los bienes y derechos en conflicto, y todo ello para cada caso. "En definitiva -concluye-, el poder de control de los contenidos incorpora necesariamente un margen de apreciación que, en algunos casos, puede ser de gran amplitud, como sucede, por ejemplo, con el control de la veracidad de la información”.

${ }^{11}$ Recommendation (2000) 23 of the Committe of Ministers to member states on the independence and functions of regulatory authorities for the broadcasting sector (20 de diciembre de 2000)

${ }^{12}$ Por ejemplo, según una encuesta realizada en 2004 por la Academia de las Ciencias y las Artes de Televisión entre 57 personas de diferentes procedencias y posicionamientos, el $90 \%$ se manifestaron a favor de la creación de un Consejo Audiovisual de ámbito estatal; el 82,7\% dijeron que eran partidarios de que se cree como autoridad independiente, de nueva planta: el 76,9\% reclamaban amplias competencias de control y vigilancia del cumplimiento de la legislación y el 61,5\% opinaban que debía tener poder sancionador. 
hecho de que las funciones reguladoras más básicas están en manos de la autoridad política” (Botella, 2007: 18). Esta autoridad, por otra parte, parece haber consolidado una posición de pasividad, de la que son prueba los informes de actividad de los dos últimos años, en los que las vacías casillas relativas a los expedientes incoados contrastan con una opinión pública preocupada por los contenidos que emiten las televisiones. Esta inactividad parece haber encontrado su coartada actual, por otra parte, en la adopción de un Código de Autorregulación ${ }^{13}$ firmado por todas las televisiones de cobertura nacional, que hasta la fecha no solamente se ha revelado más ineficaz que otras instituciones de autorregulación particulares y limitadas, como el Defensor del Telespectador y el Radioyente puesto en marcha en RTVE (A.García y L.Tenreiro, 2006) ${ }^{14}$, sino que difícilmente podía esperarse otra cosa a la luz de su composición, organización y procedimientos ${ }^{15}$, hasta el punto de que algunos observadores califican la puesta en marcha de este código de cortina de humo ya que no tiene sentido asumir que los operadores puedan cumplir un código voluntariamente asumido, existiendo una regulación que no se cumple (Écija, 2005: 396).

Este panorama de pasividad central contrasta, por otra parte, con la actividad e iniciativas de puesta en marcha de consejos audiovisuales por parte de diferentes administraciones autonómicas, entre las que destaca el Consell de l'Audiovisual de Catalunya, organismo de referencia no sólo en España sino también fuera, como lo acredita, por ejemplo, su relevante participación y contribución en reuniones y comités internacionales.

La esperada puesta en marcha, finalmente, de un Consejo Audiovisual de ámbito estatal, anticipada incluso por la legislación vigente en materia de la radiotelevisión de titularidad estatal ${ }^{16}$, posiblemente reciba su impulso final tras la entrada en vigor, el 19 de diciembre, de la Directiva 2007/65/CE, que obliga a los Estados miembros a promover no sólo mecanismos de autorregulación, sino también de corregulación, señalando que la autorregulación en ningún caso es suficiente y que la corregulación sirve, en este con-

${ }^{13}$ Acuerdo para el fomento de la autorregulación sobre contenidos televisivos e infancia, firmado el 9 de diciembre de 2004 por los representantes de RTVE, Antena 3, Telecinco y Sogecable. En junio de 2006 se adhirieron al mismo La Forta, Veo, Net TV y La Sexta

${ }^{14}$ En el segundo año de funcionamiento, el Comité de Autorregulación recibió un total de 359 quejas relativas a todos los canales, cifra que contrasta con las 2.179 reclamaciones recibidas en sus cuatro primeros meses de existencia por la Oficina del Defensor del Telespectador y del Radioyente de TVE, creada el 2 de febrero de 2006.

${ }^{15}$ De acuerdo con lo previsto en el Código de Autorregulación sobre contenidos televisivos e infancia, el control del cumplimiento de las obligaciones asumidas recae sobre un Comité de Autorregulación integrado por los propios operadores firmantes, productoras de contenidos y periodistas. Este Comité actúa a partir de la recepción de quejas de los usuarios, que no pueden dirigirlas directamente, sino a través de alguna de las cuatro asociaciones que integran la Comisión Mixta de Seguimiento. En el primer año se tramitaron 120 quejas y en el segundo, 359 .

${ }^{16}$ La Ley 17/2006, de 5 de junio, de la radio y la televisión de titularidad estatal, atribuye a la todavía inexistente autoridad audiovisual la supervisión del cumplimiento de la misión de servicio público encomendada a RTVE (artículo 40) 
texto, de "vínculo jurídico" entre la autorregulación y el poder legislativo nacional. No obstante, la Directiva, que deberá ser transpuesta al ordenamiento español en un plazo máximo de dos años, no obliga a poner en marcha sistemas de corregulación o autorregulación por más que los impulsa mediante la exigencia a los Estados miembros de establecer mecanismos de cooperación a través de sus "organismos reguladores independientes" 17 , lo que en una interpretación generosa del texto, podría permitir deducir que no sólo se da por supuesta la existencia de este tipo de organismos, sino que se les exige, por definición, que sean independientes (Jakubowicz, 2007).

Haciendo salvedad de las carencias existentes en España en relación con la existencia de organismos independientes de regulación y volviendo al hilo del discurso relativo a los procedimientos de control del cumplimiento por parte de los medios audiovisuales, en las líneas que siguen trataremos de ilustrar parte de la problemática que rodea al desempeño de las funciones de vigilancia, valoración y sanción encomendadas a este tipo de organismos, a partir de la experiencia extraída de tres autoridades de máxima relevancia en Europa: la Ofcom británica, el Conseil Supérieur de l'Audiovisuel francés, y el Consell de l'Audiovisual de Catalunya.

\section{El problema de la concreción de las normas}

Una primera observación que afecta a los fundamentos y justificación de la intervención pública sobre los contenidos en relación con la protección de la infancia tiene que ver con el concepto de "perjuicio" o "daño" y con la atribución de una relación causa-efecto entre contenidos emitidos por los medios, y modificación de conductas, actitudes o sentimientos en los menores expuestos a dichos contenidos. Sobre estas cuestiones, la evidencia empírica sugiere que es imprescindible extremar todas las cautelas en la medida en que parece inviable, de momento, fundamentar la acción regulatoria sobre la certeza de que unos determinados contenidos generan unos determinados efectos sobre una población identificada de manera homogénea en función de su edad (Millwood y Livingstone, 2006). Admitir que no existe base científica suficiente sobre la que sustentar de manera unívoca y universal el concepto de "efectos perjudiciales sobre los menores", clave de la intervención pública en los contenidos audiovisuales, implica, por encima de cualquier otra consideración, asumir la necesidad de una actuación caso por caso basada no tanto sobre la existencia inevitable de un perjuicio cierto, sino sobre el riesgo, igualmente temible, de que dicho daño pueda producirse. El objetivo de la intervención pública, en este sentido, debe ser reducir al máximo dicho riesgo. "Lo que está en juego -escriben Millwood y Livingstone- es la probabilidad de riesgo más que de

${ }^{17}$ Directiva 2007/65/CE, Considerando 36 y art.23 ter 
daño inevitable ya que, como también demuestra la investigación, no todos los que integran una audiencia son afectados de igual manera y muchos, parece, no son afectados de ninguna manera. Los radiodifusores, los reguladores y los padres tienen que seguir haciendo juicios equilibrados sobre el riesgo probable para algunos niños, teniendo en cuenta las condiciones de acceso a los contenidos (p.ej., horarios de emisión, audiencia a la que van dirigidos, contexto narrativo) y las condiciones de mediación (p.ej., papel de la intervención de los padres o restricciones sobre el acceso)" (Millwood y Livingstone, 2006: 199).

Este punto de partida obliga aún más, si cabe, a extremar los esfuerzos a la hora de concretar y clarificar las normas exigibles a los operadores de televisión. El análisis de los textos reglamentarios vigente en los tres sistemas analizados y la experiencia de la aplicación de los mismos pone de manifiesto, sin embargo, que esta concreción de obligaciones se revela como una imposibilidad que debe ser aceptada como núcleo del problema general de la relación entre los niveles de libertad y los de protección que son deseables y exigibles en una sociedad avanzada.

Una primera dificultad tiene que ver con la propia organización y extensión de las disposiciones que tienen por objeto la protección de los menores en relación con los contenidos de la televisión. En este sentido, el conjunto de normas vigentes identifican como contenidos que deben ser evitados con objeto de proteger debidamente a los menores aquellos que, siguiendo la terminología de la Directiva de Televisión sin Fronteras, pueden considerarse "perjudiciales" para "el desarrollo físico, mental y moral” de los menores. Dentro de éstos se suele incluir los de contenido pornográfico o que contengan escenas de violencia gratuita; aquellos que inciten a conductas peligrosas; y los que no respeten los derechos a la intimidad y a la propia imagen de los menores. Junto con este paquete de normas generales directamente alusivas a los menores, la mayor parte de los ordenamientos tienden a considerar conjuntamente la protección de los menores y de la dignidad humana (Écija, 2005: 377), a pesar de la recomendación expresa del Consejo, que considera "fundamental" tratar por separado ambas problemáticas dado que pueden requerir planteamientos y soluciones distintas ${ }^{18}$. Esta separación, que ha sido recogida en el texto de la nueva Directiva de Servicios de Comunicación Audiovisual, como vimos anteriormente, está tratada de manera notable en la regulación británica, que exige leer e interpretar conjuntamente las dos primeras secciones del Broadcasting Code, dedicada la primera de ellas a la protección de los menores de 18 años, y la segunda a los contenidos que puedan producir daño u ofensa ("harm and offence") a cualquier persona, independientemente de su edad.

Un problema adicional es el de la identificación de la unidad de observación. ¿Qué quiere decir el regulador cuando establece, por ejemplo en el ordenamiento español, que "las emisiones de televisión no

${ }^{18}$ Recomendación 98/560/CE, de 24 de septiembre de 1998, considerando 12 
incluirán programas ni escenas o mensajes de cualquier tipo" que puedan perjudicar seriamente el desarrollo de los menores? ¿ Tienen el mismo valor, en este caso, escenas concretas contenidas en un programa o en una obra cinematográfica, que los programas u obras completas? La tesis comúnmente aceptada es que para la determinación del grado de perjuicio que puede derivarse de la emisión de escenas dentro de un programa u obra cinematográfica, debe atenderse al contexto de la misma, valorando el conjunto del programa para tratar de precisar qué tipo de actitudes está fomentando o discriminando (Linde y Vidal, 2007: 523). La norma 2.3. del Broadcasting Code detalla qué se entiende por “contexto", señalando que incluye, entre otros, el contenido editorial general del programa, programas o serie en el que un contenido ofensivo pueda ser emitido; la hora de emisión y qué otros programas están ubicados antes y después; la dimensión y composición previsible de la audiencia y las expectativas de la misma; el impacto de ese material sobre telespectadores que puedan haberse encontrado con él de manera accidental o no buscada, etc.

Pero la verdadera dificultad se encuentra a la hora de concretar el sentido y aplicación de todas estas normas y especialmente de los conceptos básicos sobre los que descansan y se construyen. En el caso de la regulación británica, la Communications Act de 2003 exige a Ofcom que establezca las reglas que deben seguirse en los contenidos de televisión y radio, señalando que dichas reglas deben tener como objetivo, entre otros, el asegurar que se aplican "normas generalmente aceptadas"19. El Broadcasting Code elaborado por Ofcom en cumplimiento de este mandato no entra en la precisión del concepto y se limita a transcribirlo casi literalmente ${ }^{20}$. La respuesta de esta autoridad reguladora a las 71 instituciones y personas que presentaron comentarios a la redacción del Broadcasting Code durante la fase de discusión pública del mismo, solicitando una definición más precisa, es un claro ejemplo de hasta qué punto son abiertos los conceptos manejados en el ordenamiento de contenidos audiovisuales. En su respuesta, Ofcom se niega a entrar en definiciones, admitiendo que tanto el concepto de "normas generalmente aceptadas" como el de "daño y ofensa" son conceptos que cambian, que deben ir siendo precisados a partir de investigación sobre audiencias y que por lo tanto no debe incluirse una definición de los mismos en el Broadcasting Code ${ }^{21}$.

\footnotetext{
${ }^{19}$ Communications Act 2003, 319(1)(f)

${ }^{20}$ Rule 2.1. "Generally accepted standards must be applied to the contents of televisión and radio services so as to provide adequate protection for members of the public from the inclusion in such services of harmful and/or offensive material"

21 "We recognise the concern that many respondents express about the change in language in this area of regulation. However, this directly reflects the change in the law as drafted in the Act. The terminology of 'harmful and offensive' material and 'generally accepted standards' has replaced the previous wording which required that material should not offend against 'good taste and decency (...) We do not believe that a meaning of 'generally accepted standards' should be contained within the Broadcasting Code, as it is an issue which is subject to change, and our understanding will be underpinned by on-going audience research". Consultation on the proposed Ofcom Broadcasting Code, section two, General Summary of Responses
} 
Abundando en la misma idea, desde el propio Broadcasting Code se advierte a los operadores que Ofcom puede ofrecer asesoramiento general sobre la interpretación de dicho código, en el entendimiento de que tal asesoramiento en ningún caso podrá afectar a la capacidad discrecional de la entidad para juzgar, lo que equivale a decir que incluso la propia interpretación que Ofcom haga de sus normas en respuesta a la consulta de un potencial afectado por la instrucción de un caso, podría no ser la interpretación que se aplique luego a la decisión sobre dicho caso ${ }^{22}$.

Otro ejemplo lo encontramos en la Ley de la Comunicación Audiovisual de Cataluña de 2005, que a la hora de tipificar las infracciones muy graves, cuya sanción directa es la suspensión de la actividad durante un plazo de hasta tres meses (Art.136,1), incluye el incumplimiento de los principios básicos de la regulación de los contenidos audiovisuales, entre ellos el de "respetar el deber de protección de la infancia y la juventud de acuerdo con los términos que establecen esta ley y la legislación aplicable en esta materia” (art.80,h). Lo relevante, a los efectos que comentamos, es que para determinar si se ha cometido esta infracción, la ley remite a la propia instrucción del Consell de l'Audiovisual de Catalunya (art.132,b), es decir, se tipifica como infracción el cumplimiento de unos principios indeterminados, lo que se trata de compensar, en palabras de Joaquín Tornos, "mediante la discutible remisión que realiza la propia ley a una instrucción del CAC para definir y explicitar tales principios. La indeterminada tipificación legal, así como la remisión, entendemos que puede ser cuestionada desde el punto de vista del respeto al principio de legalidad" (Tornos Mas, 2007).

Finalmente y como muestra de los riesgos de recurrir a elementos externos en busca de ayuda que permita concretar la existencia de infracciones, cabe citar la normativa dictada en Cataluña en materia de protección de los niños y adolescentes, que completa y amplía la relativa a comunicación audiovisual en un aspecto tan fundamental como es la precisión del concepto jurídico de "perjuicio" causado a los menores en el ámbito de los medios de comunicación. En concreto, dicha normativa precisa que "se consideran imágenes, mensajes u objetos perjudiciales para los niños y los adolescentes aquellos que inciten a la violencia, conductas tipificadas en el ordenamiento penal y aquellas que son contrarias a los derechos fundamentales o a los principios democráticos establecidos en la Constitución y en las leyes que los desarrollan, así como también los contenidos pornográficos o que inciten al consumo de sustancias o a la comisión de actuaciones, que generen adicciones perjudiciales para la salud" 23 . Advirtiendo de la dificultad de concretar para cada caso la existencia efectiva de un perjuicio objetivo, el texto va más allá al exigir en la instrucción de los procedimientos, la presentación de un informe por parte de la unidad directiva competente

${ }^{22}$ The Ofcom Broadcasting Code (introducción.)

${ }^{23}$ Artículo 3.2 del Decreto de la CA de Cataluña 75/2006, de 11 de abril, de desarrollo de la Ley del Parlamento de Cataluña 8/1995, de 27 de julio, de atención y protección de los niños y los adolescentes, en el ámbito sancionador. 
en el ámbito de la familia, respecto a si el hecho que ha dado lugar al procedimiento, "ha producido o podido producir", el perjuicio serio a que se refiere la ley. Este informe debe ser emitido en un plazo de quince días (artículo 6.4).

¿Se pueden concretar más las normas para reducir el amplio margen dejado a la interpretación subjetiva? La clasificación de programas y su ubicación en franjas horarias, con obligación de indicación de las edades para las que un determinado programa no está recomendado, ha sido, hasta la fecha, el mecanismo principal en las políticas de protección de los menores en relación con los medios audiovisuales dictadas en Europa. El objetivo es asegurar, en la medida de lo posible, que los programas no adecuados para menores son emitidos fuera de las horas en las que se supone que éstos están viendo la televisión y, por otro lado, que todos los programas son señalizados de manera que puede saberse de antemano en qué medida son o no adecuados para cada grupo de edad. Pero aún así, los criterios para dicha clasificación son bastante ambiguos en muchos casos. Por ejemplo, ¿qué significa presentar de manera positiva "situaciones de corrupción institucional (pública o privada)", que es uno de los criterios para determinar que un programa no es adecuado para menores de 13 años, según se define en el Código de Autorregulación firmado por las televisiones en España?24. A este respecto, la Instrucción publicada en diciembre de 2007 por el Consejo del Audiovisual de Cataluña relativa a señalización orientativa representa, sin duda alguna, un esfuerzo notable para objetivar los criterios de calificación de los programas. Dicha Instrucción establece que a la hora de clasificar y señalizar los programas que emiten, los prestadores de los servicios de televisión deben atender a la presencia en los mismos de un conjunto de siete variables: violencia; sexo; miedo y angustia; drogas; discriminación; racismo y xenofobia; lenguaje grosero; y conductas y valores incívicos, para cada una de las cuales se introducen además variables de intensidad (número de veces, etc) y contextualización ${ }^{25}$. Este afán objetivador y cuantificador no elimina, como es obvio, la necesidad de una interpretación para cada caso, pero reduce, al menos aparentemente, la amplitud de dicha interpretación.

\section{El ejercicio de la función de control}

En este entorno de imprecisión conceptual y jurídica, ¿ cómo desarrollar de mejor manera la función de control sobre el desempeño de los medios audiovisuales? La existencia de procedimientos claros, detalla-

${ }^{24}$ Criterios orientadores para la clasificación de programas televisivos, incluido como anexo al Código de Autorregulación sobre Contenidos Televisivos e Infancia, de 9 de diciembre de 2004.

${ }^{25}$ Acuerdo del CAC 296/2007, de 19 de diciembre, por el cual se aprueba la Instrucción general del Consejo del Audiovisual de Cataluña sobre protección de la infancia y la adolescencia, señalización orientativa y derecho a la información de las personas usuarias de los servicios de televisión. 
dos y públicos, reduce sin duda el riesgo de indefensión e introduce garantías en el sistema ${ }^{26}$. La posibilidad de incluir el testimonio, defensa y argumentación de los operadores afectados durante las distintas partes de la instrucción es igualmente un elemento clave. Un ejemplo de este tipo de procedimientos detallados y transparentes lo encontramos en las directrices dictadas por Ofcom tanto para la tramitación de quejas como para el establecimiento de sanciones. Pero junto con la necesidad de extremar la calidad de los procedimientos, la experiencia de Ofcom, CSA y CAC revela otras cuestiones clave, entre las que cabe señalar las que se cita a continuación.

\subsection{El papel de los usuarios}

¿De dónde parte la iniciativa de comprobación del cumplimiento de las obligaciones? A diferencia del sistema americano, en el que la FCC actúa sólo a instancias de parte, es decir, a partir de la denuncia de espectadores (Betancor, 2007), en los tres sistemas europeos analizados las autoridades reguladoras actúan bien a instancias de parte o bien de oficio, aunque con diferencias. De las tres analizadas, la regulación catalana es la única que reconoce de manera explícita el derecho de cada usuario individual a dirigirse al Consejo Audiovisual de Cataluña si considera que se han vulnerado sus derechos o que se ha producido un incumplimiento de la regulación en materia de contenidos y de publicidad ${ }^{27}$. En la regulación británica, este derecho está reconocido de manera implícita por cuanto la Communications Act de 2003 exige a Ofcom que establezca procedimientos para la tramitación y resolución de las quejas que puedan producirse acerca del cumplimiento de las normas que pueda dictar la propia Ofcom en desarrollo de lo previsto por la propia ley ${ }^{28}$. En consecuencia y como efecto del reconocimiento legal del derecho de los usuarios a dirigirse a la autoridad reguladora en relación con contenidos de programas, tanto Ofcom como el CAC tramitan y dan respuesta a la totalidad de las quejas y reclamaciones recibidas y cuentan con sendos procedimientos para la recepción, tramitación, respuesta y resolución de las mismas, lo que no es el caso del Conseil Supérieur de l'Audiovisual, que atribuye a la correspondencia recibida de los telespectadores un papel más próximo al de buzón de quejas que al de ventanilla de recepción de reclamaciones ${ }^{29}$. Sin embargo, la ley

${ }^{26}$ Ofcom, Guidelines for the handling of standards complaints and cases (in programmes, advertising and sponsorship); Ofcom, Outline procedure for statutory sanctions in content cases, (actualizadas en marzo de 2004)

${ }^{27}$ Ley del Parlamento de Cataluña 22/2005, de 29 de diciembre, de la comunicación audiovisual de Cataluña, art.88,3.

${ }^{28}$ Communications Act 2003, 325 (2)

${ }^{29}$ Por ejemplo, en el Informe de actividad correspondiente al año 2006 se indica que "tanto si expresan simples críticas como si transmiten protestas vehementes o peticiones de información, las cartas y los correos electrónicos que le dirigen los oyentes y los telespectadores representan para el CSA un verdadero 'barómetro' que le permite tomar la medida de las reacciones del público a los programas difundidos" (Conseil Supérieur de l'Audiovisuel. Rapport d'activité 2006. p149) 
francesa sí reconoce el derecho de las organizaciones profesionales y sindicales representativas del sector de la comunicación audiovisual, al Consejo nacional de las lenguas y las culturas regionales y a las asociaciones familiares así como a las asociaciones que tengan por objetivo la defensa de los intereses de los telespectadores, a dirigirse al CSA para instarle a la puesta en marcha de requerimientos dirigidos a los operadores de televisión ${ }^{30}$.

Una cuestión interesante en relación con el papel de los usuarios es la de la actuación coordinada de los mismos a través de las quejas "asociadas" que utilizan un mismo texto facilitado por asociaciones, grupos de interés, etc. El CAC y Ofcom tramitan como una única queja las recibidas de esta manera ${ }^{31}$. El riesgo de sobre-representación de los grupos y minorías organizados, cuestión que igualmente suscita preocupación, disminuye, por otra parte, en la medida en que aumenta el número de ciudadanos que no sólo son conscientes de que pueden actuar, sino que además comprueban que su iniciativa genera actividad de respuesta. Para lograr este tipo de notoriedad y respaldo, es imprescindible dedicar recursos destinados a dar a conocer la existencia, manera de actuar y procedimientos de contacto, de las "ventanillas" habilitadas por los organismos reguladores. Ofcom, por ejemplo, evalúa periódicamente el nivel de conocimiento que tienen los usuarios respecto de los servicios de tramitación de quejas. En la encuesta al respecto realizada en 2006, sólo el $41 \%$ de los usuarios sabían cómo había que realizar el primer contacto para tramitar una queja relativa a la $\mathrm{BBC}$ y un $12 \%$ para quejas relativas a otros canales privados, frente al $72 \%$ que sabían a quién dirigirse para una reclamación sobre servicios financieros; el 74\%, para servicios de gas o electricidad y el $72 \%$, para telecomunicaciones ${ }^{32}$.

\subsection{Qué se controla}

En un entorno caracterizado por la multiplicación de la oferta de canales propiciada por la digitalización, no tiene sentido vigilar de manera exhaustiva todos los contenidos, lo que convertiría a los organismos reguladores en macroestructuras dedicadas al visionado de cientos de miles de horas de contenidos audiovisuales. En la actualidad, según datos de la Plataforma Europea de Autoridades Reguladoras, prácticamente todos los países han abandonado la práctica del seguimiento exhaustivo de lo que se emite por televisión y han optado por sistemas que combinan la exhaustividad en el seguimiento de determinados tipos de programas o franjas, con el seguimiento y análisis a partir de la recepción de quejas de los usuarios y con el control selectivo a partir de procedimientos muestrales. En algunos casos, además, la

${ }^{30}$ Loi 86-1067 du 30 septembre 1986 relative à la liberté de Communications, art 42

${ }^{31}$ Memoria del Consell de l'Audiovisual de Catalunya, 2006, p 5

32 Ofcom, The Consumer Experience. Research Report, 16 November 2006 
monitorización de los canales está externalizada ${ }^{33}$. En Francia, el CSA mantiene el seguimiento exhaustivo de los canales que emiten en abierto, lo que supuso en 2005 el visionado de más de 50.000 horas de programación por parte de las 60 personas dedicadas a ello dentro de la Dirección de Programas (sobre una plantilla total de 290) ${ }^{34}$. Este seguimiento ha permitido al CSA generar una base de datos con más de 16.000 programas clasificados y señalizados por edades ${ }^{35}$. Además, el CSA realiza un control selectivo, sobre periodos temporales, de las cadenas de cable y satélite así como un seguimiento puntual sobre los programas que hayan sido objeto de quejas por parte de los telespectadores.

Por lo que se refiere a Ofcom, la agencia británica basa el desarrollo de su función de supervisión sobre el doble pilar de las quejas de los usuarios y de un control basado en técnicas muestrales. El CAC, finalmente, realiza un seguimiento diario de TV3 y K3/33, analiza la idoneidad de todas las series emitidas en la franja horaria protegida de estos canales, realiza un seguimiento de todos los espacios informativos y analiza también programas a partir de las quejas canalizadas por los telespectadores a través de la Oficina de Defensa de la Audiencia.

\subsection{La cuestión de la independencia}

Cuando se atribuye a organismos como Ofcom, el CSA o el CAC la potestad de imponer sanciones que implican la suspensión temporal o total del título habilitante en relación con la infracción de las normas relativas a la protección de la infancia ${ }^{36}$ e incluso, como sucede en el caso del CAC, la de adoptar medidas cautelares que pueden implicar igualmente la suspensión temporal de la emisión ${ }^{37}$; y cuando la imposición de este tipo de sanciones recae sobre determinadas personas, miembros del organismo -en el caso catalán, se exige el voto favorable de la mayoría absoluta del Pleno del Consejo ${ }^{38}$, la cuestión de la independencia se suscita de manera inmediata y obliga a extremar las precauciones. Cabe preguntarse en qué medida la independencia puede ser exigida por medio de normas o es más bien un objetivo ético. Ahora bien, sin entrar en la discu-

\footnotetext{
33 26th EPRA Meeting, Sofia, 3-5 October 2007. WGIII: Technical \& Practical Aspects of Monitoring. Information Paper.

${ }^{34}$ Conseil Supérieur de l'Audiovisuel. Rapport d'Activité, 2005

${ }^{35}$ La protection de l'enfance et de l'adolescence à la televisión et à la radio. Bilan de l'action du CSA, Octobre 2006

${ }^{36}$ La atribución a las entidades de regulación audiovisual de la potestad de sanción en relación con infracciones que afecten a contenidos, es discutida por diversos autores, principalmente a partir de la consideración de que al afectar al derecho de información esta potestad debería quedar reservada al poder judicial, según señala Joaquín Tornos, para quien “debería negarse en estos casos la potestad sancionadora a las entidades de regulación, a las que sí podría reconocerse la capacidad para denunciar los hechos ante las instancias judiciales, acompañando a esta denuncia la adopción de medidas cautelares que deberían ser ratificadas o levantadas de modo inmediato por el poder judicial" (Tornos, 2002:223).

${ }^{37}$ Ley del Parlamento de Cataluña 2/2000, de 4 de mayo, del Consejo Audiovisual de Cataluña, art.3,bis

${ }^{38}$ Acuerdo del CAC de 3/2001, de 28 de febrero, por el cual se aprueba el estatuto orgánico y de funcionamiento del Consejo del Audiovisual de Cataluña, art.34,3
} 
sión sobre el alcance o el contenido de los poderes de sanción atribuidos a estos organismos, en la medida en que se fijan condiciones respecto a los procedimientos de designación y término del periodo de servicio de sus miembros así como respecto a sus incompatibilidades y responsabilidades y en la medida, además, de que cuentan no sólo con autonomía de gestión, sino también con recursos suficientes para llevar a cabo su misión, se reduce el ángulo de apertura de los procesos de toma de decisiones y con ello el riesgo de arbitrariedad. En palabras de Joaquín Tornos, "el tipo de composición y el estatuto de sus miembros determinan la independencia del ente y, por tanto, su razón de ser” (Tornos, 2002: 225).

Algunos de los temas clave en relación con la cuestión de la independencia tienen que ver con los riesgos de representación política asociados a la designación de los miembros por medio de mayorías parlamentarias, incluso aunque se trate de mayorías reforzadas, procedimiento planteado inicialmente como mecanismo de protección de su independencia frente a otros procedimientos, pero que conduce a otro riesgo no menor de reproducción de las minorías y mayorías parlamentarias (Tomás, 2006: 73-76). Otro tema es el de la inamovilidad de los miembros, que debe ser asegurada para evitar precisamente que puedan ser cesados cuando son incómodos, riesgo que no desaparece cuando el nombramiento se realiza por mayoría reforzada ${ }^{39}$. El perfil de los miembros es también objeto de debate, ya que aunque se tiende a considerar fundamental la competencia de éstos en las materias sobre las que deben juzgar (Tornos Mas, 2003: 482, 483), existe también el riesgo de "captura informativa” y de "captura reguladora" de los mismos, esto es, la posibilidad de que su proximidad profesional al mercado y a los actores del mismo termine afectando tanto a su selección de las fuentes de información como a su independencia de criterio a la hora de tomar decisiones (Orriols y Pons, 2007: 187-226).

A pesar de todos los esfuerzos realizados, el panorama de las autoridades independientes que existen en Europa en relación precisamente con su independencia dista de ser satisfactorio, como advierte un informe de EUMAP que señala, por otra parte, que no existe un único 'modelo' que satisfaga las necesidades de todos los reguladores en lo que se refiere a su independencia y concluye que los mecanismos y condiciones establecidos para asegurar la independencia de los organismos reguladores son condición necesaria pero no suficiente, y “al final del día, es la cultura política y la tradición existente en un determinado país lo que alimenta la actitud prevalente hacia los reguladores no gubernamentales" ${ }^{40}$.

\footnotetext{
${ }^{39}$ Vid., al respecto, Joaquín Tornos Mas, "El Consejo del audiovisual de Cataluña”, op.cit., en el que advierte que la inamovilidad de los miembros del CAC señalada en el art. 7 de la Ley 2/2000, de 4 de mayo, del Consejo Audiovisual de Cataluña, queda revocada por la Ley del Parlamento de Cataluña 14/2005, lo que significa, en opinión de Tornos, "una clara reducción de las garantías en la independencia de los miembros del CAC en el ejercicio de sus funciones".

${ }^{40}$ EU Monitoring and Advocacy Program (EUMAP), Television Across Europe: regulation, Policy and Independence. October 11, 2005.
} 


\section{Algunos datos}

La protección debida de los menores en relación con el contenido de los medios audiovisuales exige preguntarse por la eficacia de las medidas de corrección, disuasión o sanción que puedan adoptarse. ¿Puede medirse esta eficacia en función del número de actuaciones realizadas por el organismo a quien corresponda la función de control, en cuyo caso se corre el riesgo de atender más a la eficiencia y eficacias administrativas que a sus efectos correctores y positivos sobre la sociedad? ¿ $\mathrm{O}$ más bien puede considerarse un signo de eficacia la disminución de dichas actuaciones en el tiempo, posible demostración de la acción pedagógica propiciada por las actuaciones previas?

Aunque no es posible extraer conclusiones de la comparación de datos provenientes de entidades con realidades operativas y funcionales muy diferentes, sí se puede formular algunas observaciones con carácter general respecto a la capacidad de las mismas para dar respuesta a las preocupaciones, temores y demandas planteadas en nuestras sociedades respecto a la protección de los menores en relación con los contenidos de las televisiones.

\subsection{La acción de los ciudadanos}

La primera observación tiene que ver con el volumen de quejas y reclamaciones recibidas en cada organismo. El CSA recibió en 2005 un total de 9.239 correos electrónicos y cartas (media mensual: 770), que bajaron a 6.485 en 2006 (media mensual: 550), descenso que el organismo explica por las mejoras introducidas en el espacio de consultas disponible en su página web. Tres cuartas partes de estos mensajes corresponden a quejas sobre la televisión y, dentro de este grupo, las quejas sobre contenidos se refieren, en primer lugar, a imágenes o programas no adecuados para menores y, en segundo, a la retransmisión de

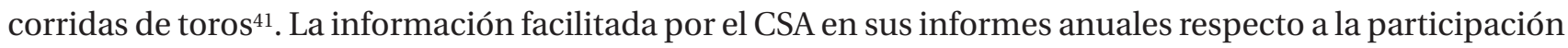
del público es escasa, desordenada y poco relevante.

Por su parte, el CAC -con capacidad de actuación sobre un volumen de canales ridículo en número si lo comparamos con los que están bajo la tutela del CSA o de Ofcom-, recibió en 2005 un total de 751 quejas canalizadas a través de la Oficina de Defensa de la Audiencia, de las cuales 532 se referían al ámbito de la programación. En 2006 recibió un total de 354 quejas diferenciadas y 14.308 quejas asociadas. De éstas, 227 fueron en relación con contenidos televisivos (13.919 quejas asociadas) ${ }^{42}$.

${ }^{41}$ Todos los datos utilizados en esta sección correspondientes al CSA están extraídos de los informes de actividad del organismo correspondientes a los años 2005 y 2006.

${ }^{42}$ Todos los datos utilizados en esta sección están extraídos de las Memorias anuales del CAC correspondientes a los años 2005 y 2006 
Ofcom, finalmente, recibió en el periodo comprendido entre 1 de abril de 2005 y 31 de marzo de 2006 un total de 14.227 quejas relativas a contenidos de televisión, de las cuales 14.025 fueron quejas relativas a normas sobre protección de la infancia y contenidos ofensivos o perjudiciales. En 2007, recibió un total de 5.405 quejas sobre contenidos similares ${ }^{43}$.

\subsection{La respuesta de los organismos de control}

En 2005, el CSA tramitó 28 requerimientos en materia de contenidos, de los que sólo uno tenía por objeto un incumplimiento de las normas sobre calificación y señalización de programas y horarios de emisión. Además, impuso tres sanciones por incumplimiento de las cuotas de difusión de programas europeos. En 2006, realizó 24 requerimientos, incluidos todos los conceptos relativos a contenidos, e impuso dos sanciones, ambas a un canal temático por no respetar las cuotas de difusión de obras europeas. A la luz de estos datos, cabe plantear como hipótesis la existencia de una relación directa entre la capacidad o incapacidad de un organismo determinado - por ejemplo, el CSA- de generar credibilidad y participación ciudadana por la vía de establecer procedimientos claros, transparentes y adecuadamente publicitados de tramitación de quejas, y la eficacia de dicho organismo en relación con su función de vigilancia y control del cumplimiento de las normas sobre protección de los menores por parte de los operadores de televisión y proveedores de servicios audiovisuales. En el caso del CSA, llama la atención, en efecto, la desproporción entre el volumen de quejas de ciudadanos relativas a contenidos no adecuados para menores, y las sanciones efectivas, como si la atención del organismo estuviera volcada de manera casi exclusiva sobre aquellas variables perfectamente cuantificables -incumplimiento de cuotas de programas europeos y publicitarias- en detrimento de aquellas que conciernen y preocupan más a los telespectadores, que son las relativas a los contenidos.

Por lo que se refiere al CAC, en 2006 realizó un total de 87 informes sobre todas las series emitidas en la franja horaria protegida de TV3 y K3/33 para comprobar la idoneidad de su calificación, como consecuencia de lo cual en 7 ocasiones se instó al canal correspondiente a cambiar la señalización. Además, acordó abrir expediente sancionador a K3 por la emisión de un videoclip señalizado como no recomendado para menores de 18 años.

Ofcom, finalmente, completó en 2005/6 un total de 1.102 casos relativos a contenidos prejudiciales u ofensivos, con el siguiente resultado: se impusieron 5 sanciones, se realizaron 172 requerimientos y se desestimaron 914 casos. El 84\% de los casos simples fueron resueltos en el plazo de 40 días fijado como objetivo en los procedimientos internos de Ofcom y el 83\% de los complejos en el plazo correspondiente de 60 días.

${ }^{43}$ Todos los datos utilizados en esta sección están extraídos de los informes anuales, Ofcom Annual Report \& Accounts 2005/06 y 2006/7 
En 2006/7 Ofcom completó un total de 1.483 casos generados a partir de las quejas indicadas más arriba, con el siguiente desglose: impuso sanciones a 4 servicios de televisión (base: 15 quejas recibidas); realizó 133 requerimientos sobre programas (base: 253 quejas); y desestimó 3.315 casos (base: 5.317 quejas)

\section{Conclusión: prudencia vs. pasividad}

Los datos mostrados ponen de manifiesto una evidente prudencia por parte de los tres organismos reguladores a la hora de sancionar, pero también son altamente reveladores de la existencia de dinámicas muy distanciadas en lo que se refiere a la actuación de los ciudadanos y a la respuesta dada desde las instituciones. Los contrastes más acusados los plantean el CSA, cuyo prestigio como institución parece claramente en declive (Bourdon, 2006) ${ }^{44}$ y Ofcom, instalado en una dinámica caracterizada por la existencia de criterios de eficacia en la atención de las quejas y en la instrucción de los procesos de análisis, evaluación, decisión y sanción.

En el cumplimiento de estos objetivos de mejora continua al servicio del ciudadano se encuentra, posiblemente, una de las claves principales para la consolidación de las autoridades independientes, cuya capacidad de intervención como entidades reguladoras debe caracterizarse, fundamentalmente, por la persecución de un objetivo de equilibrio entre todos aquellos que participan, con intereses enfrentados, en un sector como el de la comunicación, que afecta al ejercicio de derechos fundamentales. En la búsqueda de dicho equilibrio, las autoridades independientes recurren principalmente a la mediación y al fomento de la autorregulación como paso previo para una intervención directa (Tornos Mas, 2003: 483, 484).

Por otra parte, lo habitual es que los organismos de regulación del audiovisual tengan capacidad de sanción. En este sentido, la persecución de objetivos de eficacia y eficiencia de los procesos no pueden ir separadas de la imprescindible prudencia en la administración de este poder de sanción, como se ha venido insistiendo a lo largo de este artículo. "La normativa concerniente a la comunicación audiovisual, que siempre constituye una limitación de la libertad de expresión -escribe Victoria Camps-, no es ni puede ser muy precisa. (...) Dado que determinar que hay incumplimiento en cuestiones que no son estrictamente cuantificables y que tienen que ver con un daño moral o social es una tarea compleja, la apertura de expedientes sancionadores es una actividad excepcional en los consejos” (Camps, 2006: 102).

Hasta la fecha, el debate sobre los consejos audiovisuales en España y, más aún, sobre la posible puesta en marcha de una entidad de regulación independiente con competencias sobre los medios audiovisuales de

44 "El CSA no es la gran autoridad independiente señalada por los reformistas de izquierda de los años ochenta, es sólo una modesta herramienta en un mundo más liberal -con Estados debilitados- para el diálogo con los grandes grupos mediáticos”, escribe Bourdon. 
ámbito estatal, ha estado quizás excesivamente centrada en aspectos políticos, relegando a un segundo plano la discusión de los modelos y los aspectos técnicos (Botella, 2006). Es deseable que a la hora de reabrir el debate sobre la estructura, funciones y competencias del futuro Consejo Audiovisual de ámbito estatal, se integren desde el primer momento los necesarios elementos de análisis. Como se sugiere a lo largo de este texto, el equilibrio entre protección de las libertades y protección de los menores depende no sólo de las decisiones que se tomen respecto al órgano en el que residen las competencias centrales sino, fundamentalmente, de las garantías en los procesos de concreción de las normas y de aplicación de éstas. En estas garantías debería residir el núcleo del debate público sobre este tipo de organismos.

\section{Referencias bibliográficas}

Arnanz, C; García Castillejo, A; Fernández, B. (2002): ¿Queréis un buen Consejo? El sector ante el Consejo Audiovisual. Madrid: Academia de las Ciencias y las Artes de Televisión.

Betancor Rodríguez, Andrés (2007): “¿Están justificadas las autoridades administrativas de control del contenido de las emisiones?”. Revista catalana de dret públic, núm.34, pp. 31-82.

Botella Corral, Joan (2006): “Preguntas y respuestas sobre los consejos audiovisuales”. El País, 06-01-2006.

- (2007): “La regulación independiente del sector audiovisual español: una reflexión sobre problemas, perspectivas y posibilidades". Revista catalana de dret públic, núm.34, pp. 15-29.

Bourdon, Jerôme (2006): “La experiencia internacional de los organismos de regulación. El caso del CSA”. Telos, núm. 68, pp. 91-97.

Camps, Victoria (2006): “Del Senado a la experiencia del Consejo Audiovisual. Telos, núm.68, p.100-103.

Écija Bernal, Hugo (Director); Sánchez-Bleda, Pilar (Coordinadora) (2005): Hacia una nueva política audiovisual. Modelos de televisión, regulación de contenidos y consejos audiovisuales. Madrid: Écija \& Asociados Abogados.

EU Monitoring and Advocacy Program (EUMAP). Televisión Across Europe: Regulation, Policy and Independence, October 2005.

García Castillejo, A. (2003): El Consejo Audiovisual de España. Fundación Alternativas, Documento de trabajo 8/2003.

García González, A; Tenreiro Blanco, Lorena (2006): “Las reclamaciones de los telespectadores y radioyentes de RTVE”, en VV.AA.: La Ética y el Derecho en la producción y el consumo del entretenimiento. $4^{\circ}$ Congreso Internacional de Ética y Derecho de la Información. Valencia: Fundación COSO.

Jakubowicz, Karol (2007): “The Independence of Regulatory Authorities”. 25th Meeting of the European Platform of Regulatory Authorities (EPRA). Prague, 16-19 May. 
Linde Paniagua, Enrique; Vidal Beltrán, Jose María (2007): Derecho Audiovisual. Madrid: Ed.Colex, 2a edición.

Millwood Margrave Andrea; Livingstone, Sonia (2006): Harm and offence in Media Content. A review of the evidence. Bristol/Portand: Intellect Books, 2006.

Orriols i Sallés, Maria Àngels; Pons Canovas, Ferrán (2007): "La futura regulación de un consejo estatal de los medios audiovisuales”. Revista catalana de dret públic, núm. 34, pp. 187-226.

Tomás, Ferran (2006): “Equilibrios internos y externos de los Consejos Audiovisuales”. Telos, núm. 68, pp. 73-76.

Tornos Mas, Joaquín (2002): “Pluralismo y entidades de regulación”, en Tornos, J. (Coord.): Democracia y medios de comunicación. Valencia: Institut de Dret Públic - Editorial Tirant lo Blanch, pp. 213-230.

Tornos Mas, Joaquín (2003): “La potestad normativa de las autoridades administativas independientes. El caso del Consell Audiovisual de Catalunya”. Derecho Privado y Constitución, núm.17, pp. 479-498.

- (2007): “El Consejo del Audiovisual de Cataluña”. Revista catalana de dret públic, núm.34, pp. 157-186.

\section{DOCUMENTOS CITADOS}

\section{Europa}

Directiva 89/552CEE, de 3 de octubre, sobre la coordinación de determinadas disposiciones legales, reglamentarias y administrativas de los Estados miembros relativas al ejercicio de actividades de radiodifusión televisiva, modificada por la Directiva 97/36/CE, de 30 de junio.

Directiva 2007/65/CE, de 11 de diciembre de 2007, por la que se modifica la Directiva 89/552/CE.

Recomendación 98/560/CE de 24 de septiembre de 1998 relativa al desarrollo de la competitividad de la industria europea de servicios audiovisuales y de información mediante la promoción de marcos nacionales destinados a lograr un nivel de protección comparable y efectivo de los menores y de la dignidad humana.

Recommendation (2000)23 of the Committee of Ministers to member states on the independence and functions of regulatory authorities for the broadcasting sector (Adopted by the Committee of Ministers on 20 December 2000).

26th EPRA Meeting, Sofia, 3-5 October 2007. WG III: Technical \& Practical Aspects of Monitoring. Information Paper.

\section{España}

Ley 25/1994, de 12 de Julio, por la que se incorpora al ordenamiento jurídico español la Directiva 89/552/CE. Modificada por la Ley 22/1999, de 7 de junio, por la que se incorpora la Directiva 97/36/CE.

Acuerdo para el fomento de la autorregulación sobre contenidos televisivos e infancia (9 diciembre 2004).

Ley 17/2006, de 5 de junio, de la radio y la televisión de titularidad estatal.

Ley de la CA de Cataluña 2/2000, de 4 de mayo, del Consejo Audiovisual de Cataluña. 
Acuerdo del CAC 3/2001, de 28 de febrero, por el cual se aprueba el estatuto orgánico y de funcionamiento del Consejo del Audiovisual de Cataluña.

Ley de la CA de Cataluña 22/2005, de 29 de diciembre, de la comunicación audiovisual en Cataluña.

Decreto de la CA de Cataluña 75/2006, de 11 de abril, de desarrollo de la Ley del Parlamento de Cataluña 8/1997, de 27 de julio, de atención y protección de los niños y adolescentes, en el ámbito sancionador.

Acuerdo del CAC 296/2007, de 19 de diciembre, por el que se aprueba la Instrucción general del Consejo del Audiovisual de Cataluña sobre protección de la infancia y la adolescencia, señalización orientativa y derecho a la información de las personas usuarias de los servicios de televisión.

Consell de l'Audiovisual de Catalunya. Memorias 2005 y 2006.

\section{Francia}

Loi no 86-1067 du 30 septembre 1986 relative à la liberté de communication.

Conseil supérieur de l'Audiovisual. Rapport d'Activité, 2005.

Conseil supérieur de l'Audiovisual. Rapport d'Activité, 2006.

La protection de l'enfance et de l'adolescence à la télévision et à la radio. Bilan de l'action du CSA, Octubre 2006.

\section{Reino Unido}

Communications Act 2003.

Ofcom Broadcasting Code.

Consultation on the proposed Ofcom Broadcasting Code. General Summary of Responses.

Ofcom Guidelines for the handling of standards complaints and cases (in programmes, advertising and sponsorship). Reviewed March 2004.

Ofcom outline procedure for statutory sanctions in content cases. Reviewed March 2004.

Ofcom, The Consumer Experience. Research Report, 2005.

Ofcom, The Consumer Experience. Research Report, 16 November 2006.

Ofcom, Annual Report \& Accounts 2005/06.

Ofcom, Annual Report \& Accounts 2006/07. 
